\title{
MACBETHSort: a multiple criteria decision method for sorting strategic products
}

\author{
Alessio Ishizaka, Maynard Gordon \\ University of Portsmouth, Portsmouth Business School, Richmond Building, \\ PO1 3ED Portsmouth, United Kingdom \\ Alessio.Ishizaka@port.ac.uk, maynard.gordon@myport.ac.uk
}

Abstract: Efficient companies need to know which their strategic products are. For this purpose, the ABC classification based on the item's value was developed and was used for a long time. Later, it was recognised that several other criteria need to be considered and multicriteria ranking methods were applied. However, the classes have always been defined based only on a relative proportion. Therefore, the number of products in a class is independent of the actual importance of the products. In this paper, a new sorting procedure MACBETHSort is introduced, which is an evolution of the choice, ranking and rating technique MACBETH. The procedure has been validated in a real case study for assigning access and entrance solutions in $\mathrm{ABC}$ classes.

Keywords: MACBETH, MACBETHSort, Sorting, MCDA, ABC classification

\section{Introduction}

Efficient and effective product management is needed to maintain competitive advantage, especially when faced with fast moving globalised competition. Inappropriate management of sensitive products can lead to out-of-stock and market share losses. Over-management of less important products implies unnecessarily high stocking and marketing costs. Multi-criteria decision making (MCDM) techniques have long been applied to classify products as A, B, and $\mathrm{C}$ according to their strategic importance. Unfortunately, after a MCDM ranking technique has been used, a subjective percentage is applied to populate the balance in each of the $\mathrm{ABC}$ classes. In order to satisfy these percentages, we could have an unwanted situation, as:

- Products with low priority could be categorised as important just to satisfy the percentage of class A. 
- Products with a high priority could be categorised in class $\mathrm{C}$, just because the predetermined percentage of the A and B classes are already fulfilled.

- Two products having the same score could be paradoxically assigned to two different classes to avoid the percentage of a class being exceeded.

Therefore, in this paper, we suggest using an MCDM sorting technique for assigning products to classes. The aim of sorting techniques is to assign products into ordered and predefined characterised classes. It regroups similar items for descriptive, organisational or predictive applications. For this purpose, we have adapted the MCDM choice, ranking and rating technique Measuring Attractiveness by a Categorical Based Evaluation Technique (MACBETH) (Bana E Costa, De Corte, \& Vansnick, 2012), into MACBETHSort for sorting problems. This new variant has been applied for sorting products of a Small and Medum Entreprise (SME) that manufactures access and entrance solutions.

The structure of the paper is as follows: Section 2 reviews the main techniques used in the $\mathrm{ABC}$ analysis. Section 3 describes the proposed new sorting procedure: MACBETHSort. In section 4, MACBETHSort is applied in a real case study. Finally, section 5 concludes the paper.

\section{Literature review}

\subsection{Product Management}

The first technique developed for managing products is the ABC analysis (Dickie, 1951). It is based on the Pareto principle to divide products into three classes: Class A contains the most important products, moderately important products are in Class B and Class $\mathrm{C}$ contains marginally important products. Although $\mathrm{ABC}$ analysis is widely used, especially because of its simplicity; it has also been criticised because it considers only a single criterion: dollar usage. Therefore, new techniques have been developed to take into account the multi-criteria structure of the problem. A matrix with two criteria, capital usage and lead time, has been proposed by (Flores \& Whybark, 1986, 1987). However, the methodology becomes difficult to visualise, when more criteria are considered.

Flores and Whybark (1986) use a weighted sum of several normalised criteria (i.e. average unit cost, annual capital usage, criticality and lead time) into a single priority score for each item. The weights of the criteria are derived from a pairwise comparison matrix as in the analytic hierarchy process (AHP). Other researchers have applied the same technique 
(Partovi \& Burton, 1993; Partovi \& Hopton, 1994) or a slightly modified technique with fuzzy AHP (Cakir \& Canbolat, 2008), fuzzy AHP-DEA (Hadi-Vencheh \& Mohamadghasemi, 2011) and AHPSort-K-Veto (Lolli, Ishizaka, \& Gamberini, 2014).

Later, Ramanathan (2006), with inspiration from the Data Envelopment Analysis (DEA), proposes a weighted sum model; where the weights are calculated in a linear optimisation to show each product under its best profile. The advantage of this method is that we do not require any input from the decision maker. This approach may be useful for new items, where the determination of weights is difficult because of the lack of history relating to the item. The particularity of the method is that bad scores may be totally ignored. In order to limit this problem, $\mathrm{Ng}$ (2007) first asks the decision maker for an ordinal ranking of the criteria. This information is then added as a constraint in a linear optimisation model. Later, Hadi-Vencheh (2010) modifies the normalisation constraint on the weights . The squared sum (instead of the simple sum) of the weights is normalised in order to increase the distance between them and to decrease the likelihood that the weakness of an item is ignored. Dealing with the same problem, Zhou and Fan (2007) calculate the most favourable weights and least favourable weights. Both weights are then combined in a weighted sum where the decision maker subjectively defines the weights of the most and least favourable weights. Chen (2011) criticised this approach because only two extreme cases are considered and each item has its own set of weights, which makes them less comparable. He also added that a particular criterion might be neglected by receiving a weight of zero; especially if the number of criteria increases. Therefore, he proposed calculating the weights for all items and then using them to evaluate the efficiency of other items; hence the name peer-evaluation or cross-evaluation instead of self-evaluation. Then, a second objective is used to maximise the cross-efficiency of other items. This means that the cross-efficiency has the advantage of preventing unrealistic weights (i.e., all criteria weights are zero apart from one) because they are diluted due to peer-estimation. The issue with all of these proposed methods is that the weighted sum assume that the utility function of each criterion is linear, which is not necessary the case in reality. For example, the annual capital usage needs to reach a critical mass before becoming profitable.

Another issue is the attribution of the products to an importance class (A, B or C). This final sorting step follows an exogenous rule imposed by the decision maker, often based on a percentage. For example, the top $10 \%$ of the products are assigned to class A, the next $20 \%$ to class B and the last $70 \%$ to class $\mathrm{C}$. This relative sorting is misleading because if all products are marginal, class A would contain marginal products just to satisfy the predefined 
proportion. A more paradoxical consequence of this rule is that two products having a similar score could be assigned to two different classes to satisfy these proportions. This practice would lead to managing these two similar products in different ways. In other words, the proposed methods are strongly affected by the arbitrary nature of the proportions in the attribution of the items to the importance classes, without providing any objective or justifiable rules for achieving the cardinalities of these classes. It can also be observed that such an approach is not always coherent with the aim of defining clusters of products with similar characteristics.

In order to solve these issues of misleading classification, a sorting technique needs to be used. Next section will review them.

\subsection{Sorting methods}

Several multicriteria sorting methods have been proposed. The nominal classification methods treat problems where there is no preference order on the predefined groups. These methods are generally based on the computation of a similarity, indifference or closeness degree between the options to be classified and the reference options or central profiles defining the classes. Some examples of these methods are PROAFTN (Belacel, 2000), Filtering Procedures (Perny, 1998), TRINOMFC (Léger \& Martel, 2002), CLOSORT (Fernandez, Navarro, \& Duarte, 2008). These methods are not adequate for our problem because they do not incorporate the dominance relationship.

The sorting methods are designed for classification problems where the classes are completely ordered (i.e. from the best to the worst). The classes are defined either by boundary or reference (central profiles) profiles. Some examples of these methods are Electre-Tri (Yu, 1992), Electre-Tri-nC (Almeida-Dias, Figueira, \& Roy, 2012), ElectreSort (Ishizaka \& Nemery, 2014), FlowSort (Nemery \& Lamboray, 2008), FlowSort-GDSS (Lolli, Ishizaka, Gamberini, Rimini, \& Messori, 2015), PromSort (Araz \& Ozkarahan, 2007), Theseus Method (Fernandez \& Navarro, 2011), Rough Sets (Greco, Matarazzo, \& Slowinski, 2002), AHPSort (Ishizaka, Nemery, \& Pearman, 2012). In this paper, we adopt MACBETH for sorting problems. The fundamental difference with numerical value-measurement procedures is that MACBETH uses only qualitative judgements of difference in attractiveness to generate value scores for options and weights (Bana E Costa, De Corte, et al., 2012)

MACBETH has been used extensively for ranking problems (Bana e Costa, Corrêa, De 
Corte, \& Vansnick, 2002; Bana e Costa, Oliveira, \& Vieira, 2008; Bana e Costa \& Oliveira, 2012; Berrah, Mauris, \& Montmain, 2008; Roubens, Rusinowska, \& de Swart, 2006) and for choice problems (Bana e Costa \& Chagas, 2004; Bana e Costa, et al., 2002; Bana e Costa, et al., 2008; Dhouib, 2014; Fasolo \& Bana e Costa, 2014). MACBETH has also been used for sorting problems (Bana e Costa, Carnero, \& Oliveira, 2012; Bana e Costa \& Oliveira, 2002; Bana e Costa \& Oliveira, 2012). The proposed method requires to build an additive value function model to rate the options and the thresholds. The definition of the threshold is done with a bottom-up and top-down procedure. The bottom-up is as follow (Bana e Costa \& Oliveira, 2002, section 3.2):

I. Start with a fictious option characterised by the lowest score on all criteria.

II. At each stage select a new criterion and raise the score of the fictitious option to its highest level.

III. Stop to raise the profile when the decision-maker assigns the fictitious profile to a category above the previous assignment.

IV. Finally lower the score of the last investigated criterion until the decision-maker hesitates to which category the fictitious option is to be assigned.

The same procedure is repeated in a top-down approach, where all the scores are at the maximum and then gradually decreased to its minimum, criterion by criterion. If there is a discrepency between the top-down and bottom-up approach, a discussion is needed to fix the threshold.

In (Bana e Costa, Carnero, et al., 2012, section 3.2.3), the description is not so detailed but we can guess from (Bana e Costa, Carnero, et al., 2012, figure 6) that the procedure is slightly different. The first step is similar to (Bana e Costa \& Oliveira, 2002, section 3.2), but in the second step, the performance of each criterion is increased level by level and the decision-maker stops when the ficticious profile is changing category. The fourth step is therfore not needed.

This approach has several issues:

- The options are never directly compared to the limiting profiles. As the two processes are kept separately, it may exist a deviation in the evaluations. 
- The presented fictitious option in (Bana e Costa \& Oliveira, 2002, section 3.2) is highly improbable as it has all the scores on all criteria at the minimum or maximum apart from one, which has intermediate values. The fictitious option constructed in (Bana e Costa, Carnero, et al., 2012, section 3.2.3) is more realistic.

In MACBETHSort, the thresholds of the classes are defined on each criterion and then the options are compared to these thresholds. The next paragraph explains this process in detail.

\section{MACBETHSort}

Sorting methods are used to assign options to predefined groups. The groups are defined in an ordinal way, from the most to the least preferred, based on decision-maker's preferences. MACBETHSort is based on the following seven steps:

\subsection{Problem definition}

i. Define the goal, criteria $c_{j}, j=1, \ldots, m$ and options $o_{k}, k=1, \ldots, l$ of the problem.

ii. Define the classes $C_{i,}, i=1, \ldots, n$, where $n$ is the number of classes. The classes are ordered and have a label (e.g. excellent, good, medium, bad)

iii. Define the profiles of each class. This can be done with local limiting profiles $l p_{i j}$, which indicates the minimum performance needed on each criterion $j$ to belong to a class $C_{i}$, or with local central profiles $c p_{i j}$, which is given by a typical example of an element belonging to the class $C_{i}$ on the criterion $j$. We need $m \cdot(n-1)$ limiting profiles or $m \cdot n$ central profiles to define each class.

The definition of the profile is a critical step. Depending on the expertise of the decision-maker, we have three techniques:

a) The decision-maker is a real expert in the field and knows the limiting profile. This is the easiest and straightforward case.

b) The decision-maker has some expertise, so we need to help him to elicit his knowledge. We set the score of the investigated criterion at the lowest level and increase it slowly and ask the decision-maker when he feels the option should be assigned to a higher class. This trigger point defines the limiting profile. The same 
technique can be used in a top-down approach to cross-validate the bottom-up approach.

c) The decision-maker has a low expertise and can only provide a typical example for each class. This typical example constitutes the central profile.

\subsection{Evaluations}

iv. The MACBETH weighting is done through a qualitative swing weighting procedure equivalent to the quantitative swing weight procedure of SMART (Bana E Costa, De Corte, et al., 2012). The interval scale used is given in Table 1.

\begin{tabular}{|c|c|}
\hline Categories & Semantic categories \\
\hline Cat $_{0}$ & no \\
\hline Cat $_{1}$ & very weak \\
\hline Cat $_{2}$ & weak \\
\hline Cat $_{3}$ & moderate \\
\hline Cat $_{4}$ & strong \\
\hline Cat $_{5}$ & very strong \\
\hline Cat $_{6}$ & extreme \\
\hline
\end{tabular}

Table 1: Seven semantic categories

Derive the weights $w_{j}=\Phi\left(c_{j}\right)$ of the criteria $c_{j}$ by solving the linear program as in MACBETH (Bana E Costa, De Corte, et al., 2012), where $c^{+}$is at least as attractive as any other element $c_{j}$ and $c^{-}$is at most as attractive as any other element $c_{j}$

(1) minimise $\left[\Phi\left(c^{+}\right)-\Phi\left(c^{-}\right)\right]$

under the constraints

$\Phi\left(c^{-}\right)=0$ (arbitrary assignment)

$\Phi\left(c_{x}\right)-\Phi\left(c_{y}\right)=0 \quad \forall c_{x}, c_{y} \in \mathrm{Cat}_{0}$

$\Phi\left(c_{x}\right)-\Phi\left(c_{y}\right) \geq i \forall c_{x}, c_{y} \in \mathrm{Cat}_{\mathrm{i}} \cup \ldots \cup$ Cat $_{\mathrm{s}}$ with $i, s \in\{1,2,3,4,5,6\}$ and $i \leq s$

$\Phi\left(c_{x}\right)-\Phi\left(c_{y}\right) \geq \Phi\left(c_{w}\right)-\Phi\left(c_{z}\right)+i-s^{\prime}, \forall c_{x}, c_{y} \in \mathrm{Cat}_{\mathrm{i}} \cup \ldots \cup \mathrm{Cat}_{\mathrm{s}}$ and $\forall c_{w}, c_{z} \in \mathrm{Cat}_{\mathrm{i}}$

$\bigcup \ldots \cup$ Cat $_{\mathrm{s}}$ with $i, s, i^{\prime}, s^{\prime} \in\{1,2,3,4,5,6\}, i \leq s, i^{\prime} \leq s^{\prime}$ and $i>s^{\prime}$.

v. Compare pair-wise, in a judgement matrix, the difference in importance between a single option and each limiting profile $l p_{i j}$ or central profile $c p_{i j}$ for each criterion $j$. 
From the judgement matrix, derive the local attractiveness $a_{k j}$ of the option $o_{k}$ and the local attractiveness $p_{i j}$ of the limiting profiles $l p_{i j}$ or central limiting profiles $c p_{i j}$ with the linear program (1).

\subsection{Assignment to classes}

vi. Aggregate the weighted local attractiveness, which provide the overall attractiveness $a_{k}$ for the option $k(2)$ and the overall attractiveness $l p_{i}$ for the limiting profile or $c p_{i}$ for the central profiles (3).

(2) $\quad a_{k}=\sum_{j=1}^{m} a_{k j} \cdot w_{j}$

(3) $\quad l p_{i}$ or $c p_{i}=\sum_{j=1}^{m} a_{i j} \cdot w_{j}$

The comparison of $a_{k}$ with $l p_{i}$ or $c p_{i}$ is used to assign the option $o_{k}$ to a class $C_{i}$. The assignment algorithm depends on the type of profile used to define the classes:

a) limiting profiles:

If limiting profiles has been selected, the option $o_{k}$ is assigned to the class $C_{i}$ which has the $l p_{i}$ just below the overall attractiveness $a_{k}$ (Figure 1).

(4) $\quad a_{k} \geq l p_{1} \quad \Rightarrow \quad o_{k} \in C_{1}$

$l p_{2} \leq a_{k}<l p_{1} \Rightarrow \quad o_{k} \in C_{2}$

$a_{k}<l p_{n-1} \quad \Rightarrow \quad o_{k} \in C_{n}$ 


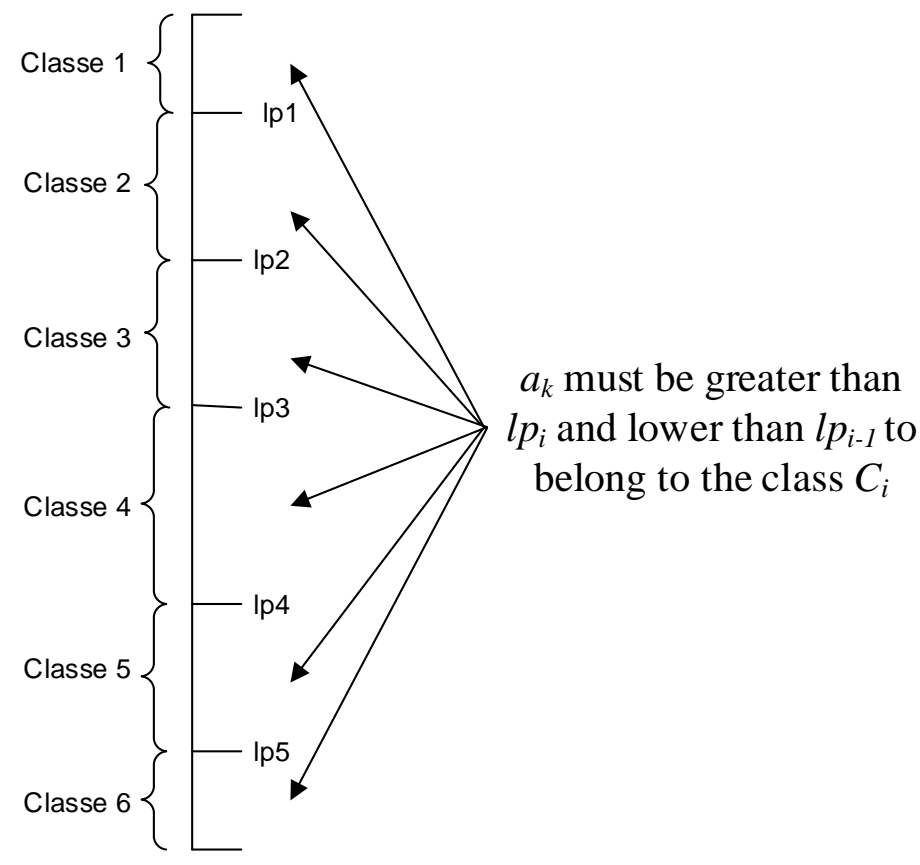

Figure 1: Sorting with limiting profiles

b) Central profiles:

As said in section 3.1, the central profile is less precise than the limiting profile and is to be used only if the decision-maker has difficulty in defining a limiting profile. In this case, a typical example of each class can be defined, which corresponds to the central profiles $c p_{i}$. The limiting profiles are deduced by $\left(c p_{i}+c p_{i+1}\right) / 2$. The option $o_{k}$ is assigned to the class $C_{i}$ which has the nearest central profile $c p_{i}$ to $a_{k}$ (Figure 2). In the case of equal distance between two central profiles, the optimistic assignment allocates $o_{k}$ to the upper class, whilst the pessimistic assignment vision allocates $o_{k}$ to the lower class.

(5)

$$
\begin{array}{ll}
a_{k} \geq c p_{1} & \Rightarrow o_{k} \in C_{1} \\
c p_{2} \leq a_{k}<c p_{1} \operatorname{AND}\left(c p_{1}-a_{k}\right)<\left(c p_{2}-a_{k}\right) & \Rightarrow o_{k} \in C_{1} \\
c p_{2} \leq a_{k}<c p_{1} \operatorname{AND}\left(c p_{1}-a_{k}\right)=\left(c p_{2}-a_{k}\right) & \Rightarrow o_{k} \in C_{1} \text { in the optimistic vision } \\
c p_{2} \leq a_{k}<c p_{1} \operatorname{AND}\left(c p_{1}-a_{k}\right)=\left(c p_{2}-a_{k}\right) & \Rightarrow o_{k} \in C_{2} \text { in the pessimistic vision } \\
c p_{2} \leq a_{k}<c p_{1} \operatorname{AND}\left(c p_{1}-a_{k}\right)>\left(c p_{2}-a_{k}\right) & \Rightarrow o_{k} \in C_{2} \\
\ldots & \Rightarrow o_{k} \in C_{n}
\end{array}
$$




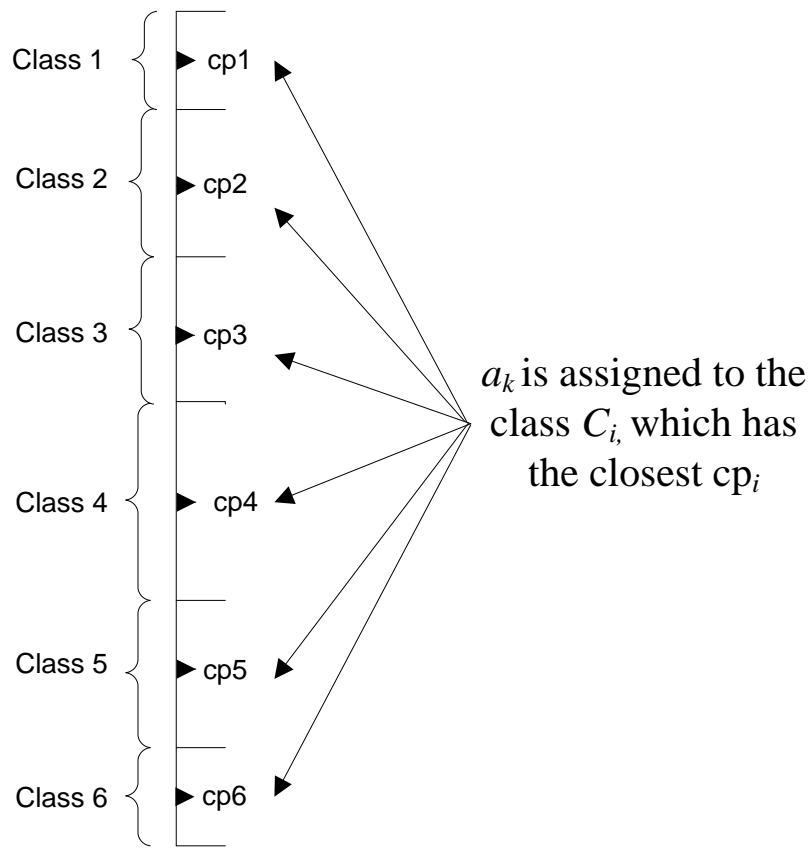

Figure 2: Sorting with central profiles

It is to note that even if called central profile, it can be decentralised when two adjacent classes have different size (Figure 3).

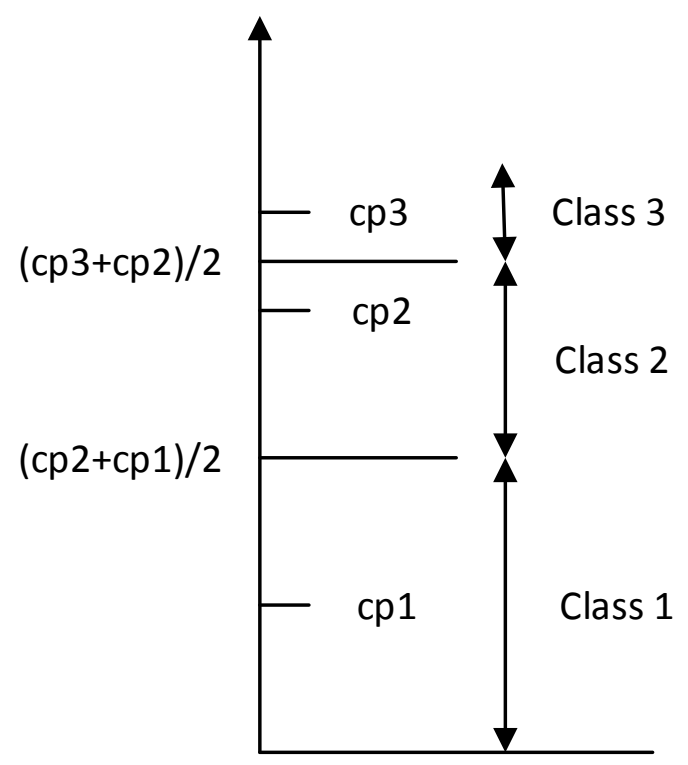

Figure 3: Central profiles with two adjacent classes of different size

vii. Repeat process iv) to vii) for each option to be classified.

\section{Case study}

In order to illustrate the validity of the proposed procedure (section 3), we describe its application in a real case study of strategic product classification. 


\subsection{Problem definition}

\section{i. Problem description}

The company in the study is a Turkish SME manufacturing access and entrance solutions.

They maintain an international presence in a number of markets with ten access and entrance solutions (Table 2). The company does not formally distinguish its products. However, in order to be more efficient, it has been decided that their products need to be classified according to their strategic importance. For this purpose, eight criteria have been selected by the manager of the company (Table 3 ).

\begin{tabular}{|c|c|}
\hline Products & Description \\
\hline Breakout & $\begin{array}{l}\text { The unique feature of this particular sliding entrance is the incorporation } \\
\text { of a 'panic break-out' system. This means that the door can both slide } \\
\text { and swing. }\end{array}$ \\
\hline Curved & $\begin{array}{l}\text { The difference with a flat fronted sliding entrance is that the door is } \\
\text { curved. It is a highly bespoke product. }\end{array}$ \\
\hline Folding & $\begin{array}{l}\text { The folding entrance is often used in situations where space restrictions } \\
\text { do not allow the use of a } 90^{\circ} \text { swing door but where automation is still } \\
\text { desired. }\end{array}$ \\
\hline All Glass & $\begin{array}{l}\text { Due to the all glass construction there are some limitations to the } \\
\text { additional operating features that are available. For the same reason } \\
\text { however, some engineering characteristics had to be rethought for the } \\
\text { delivery of this solution. }\end{array}$ \\
\hline $\begin{array}{l}\text { Grand } \\
\text { Revolving }\end{array}$ & $\begin{array}{l}\text { It is designed for high traffic-volume buildings, e.g. shopping centres, } \\
\text { mass transit hubs. It has increased passage capacity, configuration } \\
\text { options and is designed for continuous operation. }\end{array}$ \\
\hline $\begin{array}{l}\text { Multi- } \\
\text { combination }\end{array}$ & $\begin{array}{l}\text { A multifunctional entrance system that provides multiple operating } \\
\text { combinations i.e. rotating, sliding and even swing functions all in one } \\
\text { unit. It is the most versatile egress available. }\end{array}$ \\
\hline $\begin{array}{l}\text { Standing } \\
\text { Revolving }\end{array}$ & $\begin{array}{l}\text { It is a rotating door, which can have } 2,3 \text { or } 4 \text { wings. It is more energy } \\
\text { efficient than a slide or swing door system. }\end{array}$ \\
\hline $\begin{array}{l}\text { Standard } \\
\text { Sliding }\end{array}$ & $\begin{array}{l}\text { It is a door that slides to open. The special feature of this product is that } \\
\text { it is highly modular in terms of installation. }\end{array}$ \\
\hline Swing & $\begin{array}{l}\text { It is a door pivoting on double-sided hinges so that it can open either } \\
\text { way. }\end{array}$ \\
\hline
\end{tabular}




\begin{tabular}{|l|l|}
\hline Turnstile & $\begin{array}{l}\text { Type of gate that allows only one-person passage at a time. It is also } \\
\text { used to restrict passage flow to one direction. }\end{array}$ \\
\hline
\end{tabular}

Table 2: Products of the company

\begin{tabular}{|c|c|}
\hline Criteria & Explanation \\
\hline $\begin{array}{l}\text { Speed (Manufacturing } \\
\text { Processing Time) }\end{array}$ & $\begin{array}{l}\text { Access and entrance products often feature in construction } \\
\text { projects; therefore it is important they are delivered on } \\
\text { time. }\end{array}$ \\
\hline Flexibility & $\begin{array}{l}\text { Due to the international presence of the company and its } \\
\text { competitors, it is important that product offerings can be } \\
\text { adapted to comply with local laws and customs. }\end{array}$ \\
\hline $\begin{array}{l}\text { Returns on Investment } \\
\text { (RoI) }\end{array}$ & It is the net profit divided by the investment cost. \\
\hline Market Share & $\begin{array}{l}\text { The percentage of a market accounted for by a specific } \\
\text { entity. It is a key indicator of market competitiveness. }\end{array}$ \\
\hline Dependency & $\begin{array}{l}\text { The dependency upon special components or whether } \\
\text { generic ones can be used. }\end{array}$ \\
\hline Production & How complicated is production? \\
\hline Skill & What are the skills required for production? \\
\hline Labour & $\begin{array}{l}\text { How many persons are required for the production of one } \\
\text { entity? }\end{array}$ \\
\hline
\end{tabular}

Table 3: Sorting criteria

\section{ii. Class definition}

Three classes have been defined:

- The products of class A need always to be in stock and promoted though different channels such as fairs, advertisements and catalogues.

- The products of class B need to be stocked in order to satisfy $80 \%$ of actual demand. They will occasionally be promoted in large fairs and catalogues.

- The products of class $\mathrm{C}$ do not need to be in stock and no investment in promotion or future development is undertaken. 


\section{iii. Limiting profiles definition}

The limiting profiles for each class have been defined by the managing director in Table 4 .

\begin{tabular}{|l|l|}
\hline \multicolumn{1}{|c|}{ Criteria } & Limiting Profile \\
\hline Speed & $\begin{array}{l}\text { A: Six week lead-time } \\
\text { B: Three week lead-time }\end{array}$ \\
\hline Flexibility & $\begin{array}{l}\text { A: Customisable to any country and several accessories can be } \\
\text { added } \\
\text { B: Colour and size (width) options only }\end{array}$ \\
\hline RoI & $\begin{array}{l}\text { A: } 100 \% \\
\text { B: } 10 \%\end{array}$ \\
\hline Market Share & $\begin{array}{l}\text { A: } 10 \% \\
\text { B: } 5 \%\end{array}$ \\
\hline Dependency & $\begin{array}{l}\text { A: Few components are common to major brands } \\
\text { B: } 50 \% \text { of features are common to major brands }\end{array}$ \\
\hline Production & $\begin{array}{l}\text { A: Needs to be stored in a controlled environment and assembled } \\
\text { before shipping } \\
\text { B: Assembly required before shipping }\end{array}$ \\
\hline Skill & $\begin{array}{l}\text { A: Bachelor degree in engineering with one-year of continuous work } \\
\text { experience } \\
\text { B: Recent or soon to graduate }\end{array}$ \\
\hline
\end{tabular}

Table 4: Limiting profiles

\subsection{Evaluation}

\section{iv. Criteria weight assessment}

The managing director of the company was asked to use the swing weight procedure. He was first given a neutral product and he was asked on which criterion would be the improvement from neutral to good the most important and how much. He answered speed and its improvement from neutral to good speed would be extreme. We then continued to ask the same question for the next criterion until all criteria were treated. These evaluations can be found in the column "all lower" in Figure 4. Then, we asked how much more important would be the improvement from neutral to good on the speed than the improvement from 
neutral to good on the flexibility? The managing director answered very weak. All other evaluations in Figure 4 are elicited on the same way. Only the top part of the matrix is needed due to the reciprocity property. The calculated weights with (1) are shown in the column "current scale" of Figure 4. The financial (RoI and market share) and manufacturing (speed, flexibility, dependency and production) criteria receive a high importance. The staff criteria (skill and labour) receive a low weight because on the Turkish job market there is an abundance of workforce at all skill level.

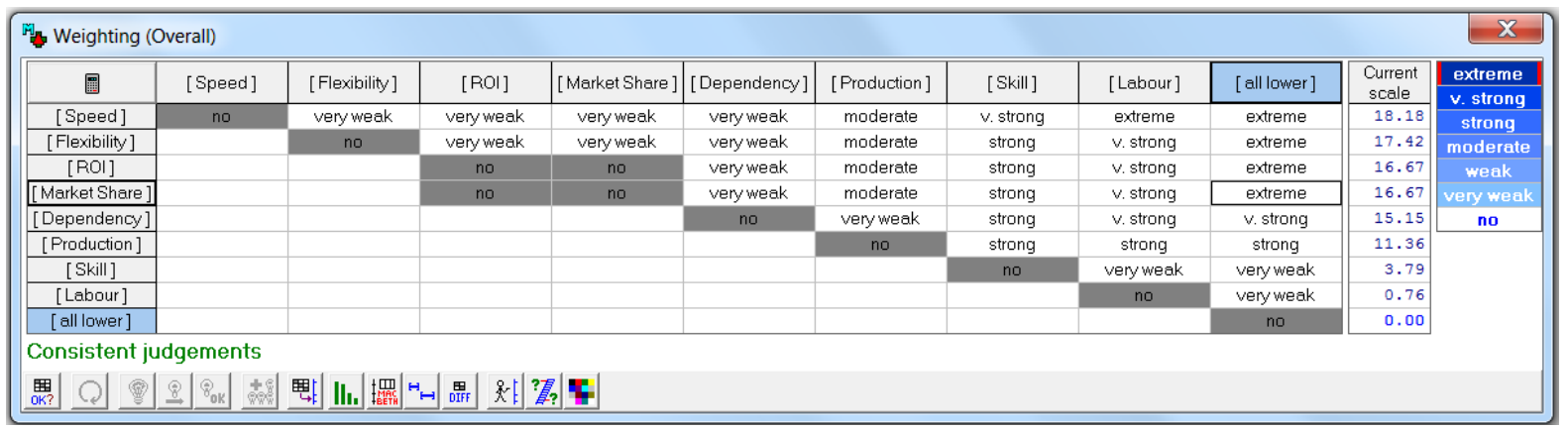

Figure 4: Pairwise comparisons and weights

\section{v. Comparison of options to limiting profiles}

For each criterion, each option is compared against the limiting profiles of the Class A and B (Table 4). For example, in Figure 5, the option Turnstile is compared in regards to speed against the limiting profile of class A (called upper) and the limiting profile of class B (called lower).

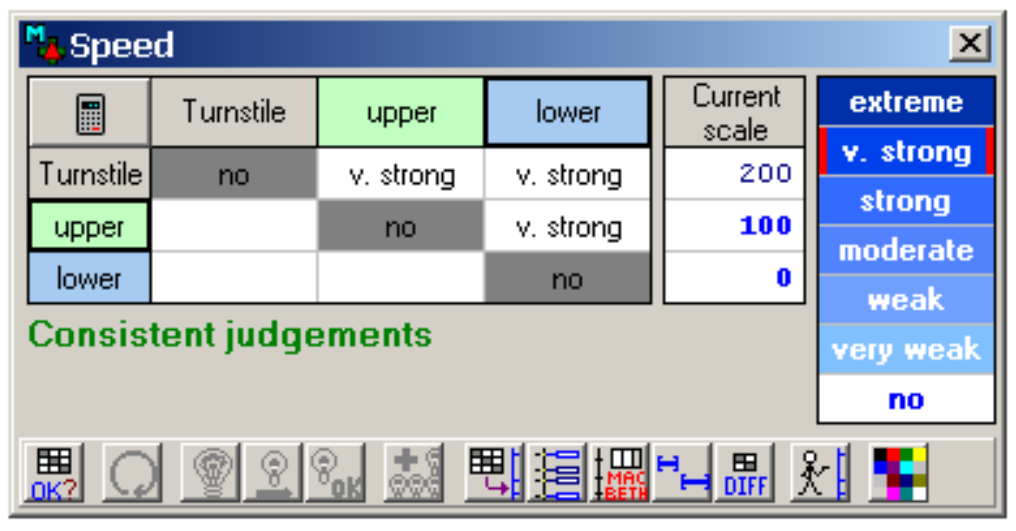

Figure 5: Pairwise comparison of an option against the limiting profiles

\subsection{Assignment to classes}

\section{vi. Score calculation}

The calculation of the overall attractiveness is calculated in the M-MACBETH software with (2). The table of scores for all options is given in Table 5 . 


\begin{tabular}{|c|c|c|c|c|c|c|c|c|c|}
\hline & 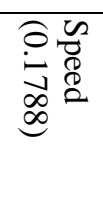 & 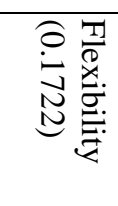 & 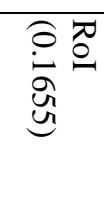 & 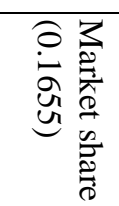 & 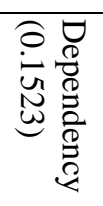 & 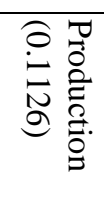 & 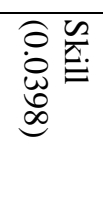 & 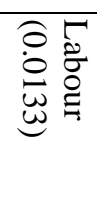 & $\begin{array}{c}\text { Overall } \\
\text { score }\end{array}$ \\
\hline Breakout & 225 & 200 & 50 & -100 & 50 & 200 & 200 & 50 & 105.16 \\
\hline Curved & 200 & 266.67 & 50 & -100 & 50 & -150 & -150 & 50 & 58.83 \\
\hline Folding & 200 & 200 & 42.86 & -125 & -100 & -150 & 200 & -100 & 31.11 \\
\hline All Glass & 200 & 300 & 50 & 200 & -100 & -100 & -100 & -100 & 97.00 \\
\hline $\begin{array}{l}\text { Grand } \\
\text { Revolving }\end{array}$ & 200 & -100 & -100 & -75 & 50 & -100 & -80 & -100 & -18.58 \\
\hline $\begin{array}{l}\text { Multi- } \\
\text { combination }\end{array}$ & -100 & -80 & -100 & -75 & 50 & -100 & -80 & 50 & $\begin{array}{l}-66.78 \\
\end{array}$ \\
\hline $\begin{array}{l}\text { Standing } \\
\text { Revolving }\end{array}$ & 200 & -100 & 50 & -66.67 & -100 & -100 & -100 & -100 & -16.02 \\
\hline $\begin{array}{l}\text { Standard } \\
\text { Sliding }\end{array}$ & 200 & 200 & 50 & -80 & 40 & 200 & 250 & 50 & 104.46 \\
\hline Swing & 200 & -100 & 42.86 & -100 & -100 & -150 & 200 & -100 & -16.41 \\
\hline Turnstile & 200 & -100 & 44.44 & -100 & 0 & -150 & 250 & -100 & 1.07 \\
\hline
\end{tabular}

Table 5: Table of scores

\section{vii. Sorting into classes}

Each product is sorted into a class using (4). For example, the product Turnstile is in class B because its overall attractiveness (second column in Figure 6) is higher than the limiting profile of class B (all lower in Figure 6) but lower than the limiting profile of class A (all upper in Figure 6).

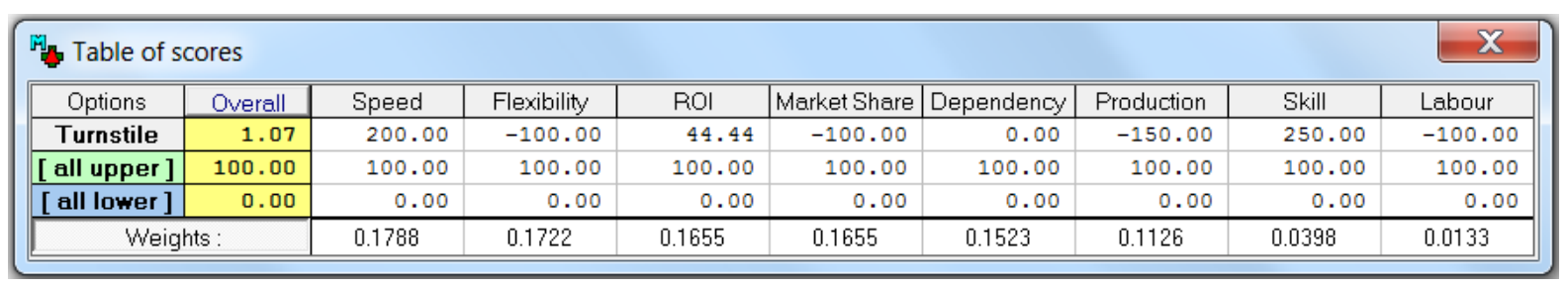

Figure 6: Sorting Turnstile with M-MACBETH

Table 6 gives the composition of the ABC classes as calculated by MACBETHSort.

However, after conducting sensitivity analysis, it was decided that the product All Glass, which is just below the threshold of the limiting profile, should belong to class A. Indeed, All Glass has currently a high market share. It is the cash cow of the company and therefore needs special attention even if it is easy to build (low score in dependency, production, skill and labour, see Table 5). In class C, apart from the Swing entrance, all of the others are revolving solutions. 


\begin{tabular}{|c|c|c|}
\hline Classes & Products & Overall attractiveness \\
\hline A & Breakout & 105.16 \\
& Standard Sliding & 104.46 \\
\hline B & All Glass & 97.00 \\
& Curved & 58.83 \\
& Folding & 31.11 \\
& Turnstile & 1.07 \\
\hline C & Standing Revolving & -16.02 \\
& Swing & -16.41 \\
& Grand Revolving & -18.58 \\
& Multi-combination & -66.78 \\
\hline
\end{tabular}

Table 6: Sorting of products in ABC

\section{Conclusion}

Decisions in business are often of significant importance and when this is the case, the first essential step is to define the problem. Six problem formulations exist in multi-criteria decision analysis: choice problems, ranking problems, sorting problems, description problems (Roy, 1981), elimination problems (Bana e Costa, 1996) and design problems (Keeney, 1992). Ranking techniques have largely been used in ABC analysis. However, in ranking techniques, the assignment of an item to a class depends upon the assignment of the other items. This is not acceptable in an ABC analysis. In sorting techniques, the assignment of items to classes is independent. This is a fundamental difference between ranking and sorting problems. Therefore, this paper proposes a new sorting technique MACBETHSort, which is a modification of the choice, ranking and rating technique MACBETH. This new method retains the advantages of MACBETH, whilst removing the problem of the high number of comparisons. However, it is to note that by reducing the size of the matrix, although we largely gain in time as we have less pairwise comparisons, we may also lose in precision. It is therefore important to validate the MACBETH scores with the decision-maker and eventually adjust them as this happened in our case study. This new technique has been validated in a real case study of a manufacturing SME.

After discussion with the case study organisation in the post-analysis, it was clear that management were impressed with the MACBETHSort procedure used. They noticed a significant reduction of time and effort in the decision process due to the structured methodology. The decision quality was also enhanced, due to a clear and consistent benchmark, a consistency check of the entered evaluations, and a sensitivity analysis 
embedded in the MACBETHSort procedure. Finally, the decision that was made is documented, unambiguous, justifiable, replicable and easily communicable.

As MACBETHSort is a generic technique, we envisage in our future research to apply it in other areas such as in risk or quality evaluation.

\section{Acknowledgement:}

I wish also to thank Ian Stevens and Salvatore Greco for their proofreading and comments.

\section{References}

Almeida-Dias, J., Figueira, J., \& Roy, B. (2012). A multiple criteria sorting method where each category is characterized by several reference actions: The Electre Tri-nC method. European Journal of Operational Research, 217, 567-579.

Araz, C., \& Ozkarahan, I. (2007). Supplier evaluation and management system for strategic sourcing based on a new multicriteria sorting procedure. International Journal of Production Economics, 106, 585-606.

Bana e Costa, C. (1996). Les problématiques de l'aide à la décision: Vers l'enrichissement de la trilogie choix-tri-rangement. RAIRO - Operations Research, 30, 191-216.

Bana e Costa, C., Carnero, M., \& Oliveira, M. (2012). A multi-criteria model for auditing a Predictive Maintenance Programme. European Journal of Operational Research, 217, 381-393.

Bana e Costa, C., \& Chagas, M. (2004). A career choice problem: An example of how to use MACBETH to build a quantitative value model based on qualitative value judgments. European Journal of Operational Research, 153, 323-331.

Bana e Costa, C., Corrêa, É., De Corte, J.-M., \& Vansnick, J.-C. (2002). Facilitating bid evaluation in public call for tenders: a socio-technical approach. Omega, 30, 227-242.

Bana E Costa, C., De Corte, J.-M., \& Vansnick, J.-C. (2012). MACBETH. International Journal of Information Technology \& Decision Making, 11, 359-387.

Bana e Costa, C., \& Oliveira, C. (2002). Assigning priorities for maintenance, repair and refurbishment in managing a municipal housing stock. European Journal of Operational Research, 138, 380-391.

Bana e Costa, C., Oliveira, C., \& Vieira, V. (2008). Prioritization of bridges and tunnels in earthquake risk mitigation using multicriteria decision analysis: Application to Lisbon. Omega, 36, 442-450.

Bana e Costa, C., \& Oliveira, M. (2012). A multicriteria decision analysis model for faculty evaluation. Omega, 40, 424-436.

Belacel, N. (2000). Multicriteria assignment method PROAFTN: Methodology and medical application. European Journal of Operational Research, 125, 175-183.

Berrah, L., Mauris, G., \& Montmain, J. (2008). Monitoring the improvement of an overall industrial performance based on a Choquet integral aggregation. Omega, 36, 340-351.

Cakir, O., \& Canbolat, M. (2008). A web-based decision support system for multi-criteria inventory classification using fuzzy AHP methodology. Expert Systems with Applications, 35, 1367-1378.

Chen, J.-X. (2011). Peer-estimation for multiple criteria ABC inventory classification. Computers \& Operations Research, 38, 1784-1791. 
Dhouib, D. (2014). An extension of MACBETH method for a fuzzy environment to analyze alternatives in reverse logistics for automobile tire wastes. Omega, 42, 25-32.

Dickie, H. (1951). ABC Inventory Analysis Shoots for Dollars, not Pennies. Factory Management and Maintenance, 109, 92-94.

Fasolo, B., \& Bana e Costa, C. (2014). Tailoring value elicitation to decision makers' numeracy and fluency: Expressing value judgments in numbers or words. Omega, 44, 83-90.

Fernandez, E., \& Navarro, J. (2011). A new approach to multi-criteria sorting based on fuzzy outranking relations: The THESEUS method. European Journal of Operational Research, 213, 405-413.

Fernandez, E., Navarro, J., \& Duarte, A. (2008). Multicriteria sorting using a valued preference closeness relation. European Journal of Operational Research, 185, 673686.

Flores, B., \& Whybark, C. (1986). Multiple Criteria ABC Analysis. International Journal of Operations \& Production Management, 6, 38 - 46.

Flores, B., \& Whybark, C. (1987). Implementing multiple criteria ABC analysis. Journal of Operations Management, 7, 79-85.

Greco, S., Matarazzo, B., \& Slowinski, R. (2002). Rough sets methodology for sorting problems in presence of multiple attributes and criteria. European Journal of Operational Research, 138, 247-259.

Hadi-Vencheh, A. (2010). An improvement to multiple criteria ABC inventory classification. European Journal of Operational Research, 201, 962-965.

Hadi-Vencheh, A., \& Mohamadghasemi, A. (2011). A fuzzy AHP-DEA approach for multiple criteria ABC inventory classification. Expert Systems with Applications, 38, 3346-3352.

Ishizaka, A., \& Nemery, P. (2014). Assigning machines to incomparable maintenance strategies with ELECTRE-SORT. Omega, 47, 45-59.

Ishizaka, A., Nemery, P., \& Pearman, C. (2012). AHPSort: an AHP based method for sorting problems. International Journal of Production Research, 50, 4767-4784.

Keeney, R. (1992). Value-Focused thinking: A Path to Creative Decision Making. Cambridge: Harward University Press.

Léger, J., \& Martel, J.-M. (2002). A multicriteria assignment procedure for a nominal sorting problematic. European Journal of Operational Research, 138, 349-364.

Lolli, F., Ishizaka, A., \& Gamberini, R. (2014). New AHP-based approaches for multicriteria inventory classification. International Journal of Production Economics, 156, $62-74$.

Lolli, F., Ishizaka, A., Gamberini, R., Rimini, B., \& Messori, M. (2015). FlowSort-GDSS - A novel group multi-criteria decision support system for sorting problems with application to FMEA. Expert Systems with Applications, 42, 6342-6349.

Nemery, P., \& Lamboray, C. (2008). FlowSort: a flow-based sorting method with limiting or central profiles. TOP, 16, 90-113.

$\mathrm{Ng}, \mathrm{W}$. (2007). A simple classifier for multiple criteria ABC analysis. European Journal of Operational Research, 177, 344-353.

Partovi, F., \& Burton, J. (1993). Using the Analytic Hierarchy Process for ABC Analysis. International Journal of Operations \& Production Management, 13, 29-44.

Partovi, F., \& Hopton, W. (1994). The Analytic Hierarchy as Applied to Two Types of Inventory Problems. Production and Inventory Management Journal, 35, 13-19.

Perny, P. (1998). Multicriteria filtering methods based on concordance and non-discordance principles. Annals of Operations Research, 80, 137-165. 
Ramanathan, R. (2006). ABC inventory classification with multiple-criteria using weighted linear optimization. Computers \& Operations Research, 33, 695-700.

Roubens, M., Rusinowska, A., \& de Swart, H. (2006). Using MACBETH to determine utilities of governments to parties in coalition formation. European Journal of Operational Research, 172, 588-603.

Roy, B. (1981). The optimisation problem formulation: criticism and overstepping. Journal of the Operational Research Society, 32, 427-436.

Yu, W. (1992). ELECTRE TRI: Aspects methodologiques et manual d'utilisation. In (Vol. 65, pp. 80): Universite Paris-Daupline.

Zhou, P., \& Fan, L. (2007). A note on multi-criteria ABC inventory classification using weighted linear optimization. European Journal of Operational Research, 182, 14881491. 